\title{
Cryptococcal meningitis: epidemiology and therapeutic options
}

This article was published in the following Dove Press journal:

Clinical Epidemiology

13 May 2014

Number of times this article has been viewed

\section{Derek J Sloan \\ Victoria Parris}

Tropical and Infectious Disease Unit, Royal Liverpool University Hospital, Liverpool, UK
Correspondence: Derek J Sloan Tropical and Infectious Disease Unit, Royal Liverpool University Hospital, Prescot Street, Liverpool, Merseyside L7 8XP, UK

Tel +44 I5I 7063835

Fax +44 I5I 7065944

Email djsloan@liverpool.ac.uk
Abstract: Cryptococcal meningitis causes morbidity and mortality worldwide. The burden of disease is greatest in middle- and low-income countries with a high incidence of human immunodeficiency virus (HIV) infection. Patients taking immunosuppressive drugs and some immunocompetent hosts are also at risk. Treatment of cryptococcal meningitis consists of three phases: induction, consolidation, and maintenance. Effective induction therapy requires potent fungicidal drugs (amphotericin B and flucytosine), which are often unavailable in low-resource, high-endemicity settings. As a consequence, mortality is unacceptably high. Wider access to effective treatment is urgently required to improve outcomes. For human immunodeficiency virus-infected patients, judicious management of asymptomatic cryptococcal antigenemia and appropriately timed introduction of antiretroviral therapy are important.

Keywords: cryptococcosis, HIV, immunosuppression, antifungal therapy, immune reconstitution inflammatory syndrome, antiretroviral therapy

\section{Introduction}

Cryptococcosis is an important infectious disease globally. The majority of illness is among patients with defective cell-mediated immunity. Human immunodeficiency virus (HIV) infection is the main risk factor, accounting for $95 \%$ of cases in middle- and low-income countries (MLICs) ${ }^{1}$ and $80 \%$ of cases in high-income countries (HICs). ${ }^{2}$ Individuals taking immunosuppressive drugs (eg, transplant recipients) constitute most of the remaining caseload, although immunocompetent hosts are susceptible in some settings.

The most common clinical presentation is cryptococcal meningitis $(\mathrm{CM})$, with over 1 million cases and 600,000 deaths per year. ${ }^{3}$ Nonmeningeal (eg, pulmonary and cutaneous) presentations also occur, ${ }^{4}$ and bloodstream infection (cryptococcemia) may disseminate to multiple sites. ${ }^{5}$

This review describes the epidemiology and management of cryptococcal disease. Worldwide distribution of the pathogen is outlined, incidence trends in patients with varying risk factors are assessed, and the prognostic implications of differing treatment protocols are highlighted.

\section{Epidemiology of the infectious pathogen}

Cryptococci are encapsulated saprophytic yeasts. Two species, transmitted by inhalation, are the principal human pathogens: Cryptococcus neoformans and Cryptococcus gattii. $^{6}$ C. neoformans was identified by Sanfelice in $1894,{ }^{7,8}$ and may be divided into two subtypes on the basis of capsular agglutination assays. ${ }^{9}$ C. neoformans var. 
grubii (capsular serotype D) is the most common, and causes $82 \%$ of cryptococcal disease worldwide. Var. neoformans (capsular serotype A) is responsible for $20 \%-30 \%$ of HIVassociated CM in northern Europe (notably France, Italy, and Denmark), ${ }^{9-11}$ but is less common in other global regions. ${ }^{12,13}$ Although both subtypes predominantly cause disease in immunocompromised individuals, several reports from the $\mathrm{US}^{14}$ and Asia ${ }^{15}$ suggest that var. grubii cryptococcosis in patients with normal immune systems is more common than previously assumed. The environmental reservoir of both subtypes is avian guano, decaying organic matter, and soil. ${ }^{8,16}$

C. gattii is traditionally associated with illness in immunocompetent individuals ${ }^{17-19}$ from tropical and subtropical regions, including Thailand, ${ }^{20}$ northern Australia, ${ }^{21,22}$ New Zealand, and Papua New Guinea. ${ }^{23-26}$ More recently, four molecular subtypes of $C$. gattii have been identified with distinct epidemiological characteristics that challenge this perspective. ${ }^{6}$ Whilst VGI (var gattii I) is the main subtype in Australasia, an outbreak of disease attributable to VGII has been described in immunocompetent patients from British Columbia, Canada. ${ }^{27-29}$ Between 1999 and 2010, 218 cases were identified on Vancouver Island. ${ }^{30,31}$ In 2006, a further case was reported on Orcas Island, Washington, USA, ${ }^{32}$ and C. gattii is now endemic throughout the Pacific Northwest of the US. ${ }^{29}$ Sporadic disease has also been notified in other parts of North America, including Florida, North Carolina, Rhode Island, New Mexico, Michigan, Georgia, and Montana. ${ }^{33}$ Additionally, C. gattii subtypes VGIII and -IV are more likely to be found in HIV-infected than immunocompetent patients. These strains may account for $2.4 \%-30 \%$ of HIV-associated cryptococcosis in some parts of Central and South America ${ }^{6}$ and southern Africa. ${ }^{34-37}$ The burden of human disease due to C. gattii is probably underrecognized, as many laboratories do not undertake detailed speciation of cryptococci. ${ }^{6}$

The environmental reservoirs of $C$. gattii are incompletely understood. In Australia, India, and other Asian countries, it has been isolated in eucalyptus trees. ${ }^{38}$ In British Columbia, it has been isolated from noneucalyptus tree species, soil, air, freshwater, and seawater. ${ }^{29}$ Discovery of this organism in heterogeneous biogeoclimatic zones suggests that its ecological niche was previously underestimated or that its distribution is expanding. ${ }^{39,40}$ Possible explanations for a changing distribution include climate change or altered land-use practices, such as logging.

\section{HIV as a risk factor}

The largest influence on the epidemiology of cryptococcal disease over the last 30 years has been the evolution of the HIV pandemic. Figure 1 shows that a fivefold increase in the incidence of cryptococcosis in France from 1985 to 1993 was almost entirely due to burgeoning disease in HIV-infected patients, while the number of cases in HIVuninfected patients remained stable. ${ }^{41}$ Similar trends were observed in other HICs. In the UK, the number of annual cryptococcal case notifications rose from 13 (8\% HIVassociated) in 1982 to 66 (83\% HIV-associated) in $1991 .{ }^{42}$ Of 517 cryptococcal infections in New York City in 1991, $96 \%$ were HIV-related. ${ }^{43}$

HIV-infected patients are mainly at risk of cryptococcosis when they become very immunosuppressed and their CD4 count drops below 100 cells/ $\mu \mathrm{L} .{ }^{44,45}$ Consequentially, Figure 1 indicates that after the development of effective combination antiretroviral therapy (ART) in 1997, the upsurge in new cases of cryptococcal disease from HICs was reversed and incidence began to decline. ${ }^{46-48}$ From 1997-2001, France saw a $46 \%$ decrease in cases, ${ }^{41}$ from 1996 to 2007, incidence per 1,000 persons in the UK fell from three to $0.2,{ }^{49}$ and from 1992 to 2000, incidence per 1,000 persons in Atlanta, Georgia, USA fell from 66 to seven. ${ }^{50}$

Figure 2 shows that disease trends in MLICs have been much worse. It is well recognized that sub-Saharan Africa has been the global region most heavily affected by HIV, with an estimated 2.6 million new infections per year at the peak of the epidemic in $1997 .{ }^{51}$ Contemporaneously, in the 1990s, CM became the leading cause of adult meningitis in many African countries, including Malawi

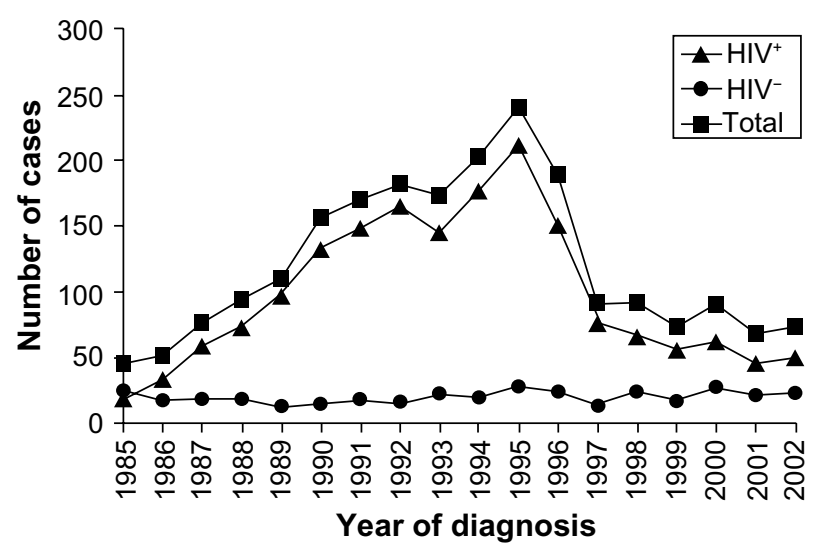

Figure I Evolution of the incidence of cryptococcosis, by year of diagnosis in France (I985-200I), as reported to the National Reference Centre for Mycosis. Note: Reproduced with permission from Dromer F, Mathoulin-Pelissier S, Fontanet A, Ronin O, Dupont B, Lortholary O, Epidemiology of HIV-associated cryptococcosis in France (1985-200I): comparison of the pre- and post-HAART eras, AIDS, I8:555-562.41 Promotional and commercial use of the material in print, digital or mobile device format is prohibited without the permission from the publisher Lippincott Williams \& Wilkins. Please contact journalpermissions@lww.com for further information. Abbreviation: HIV, human immunodeficiency virus. 


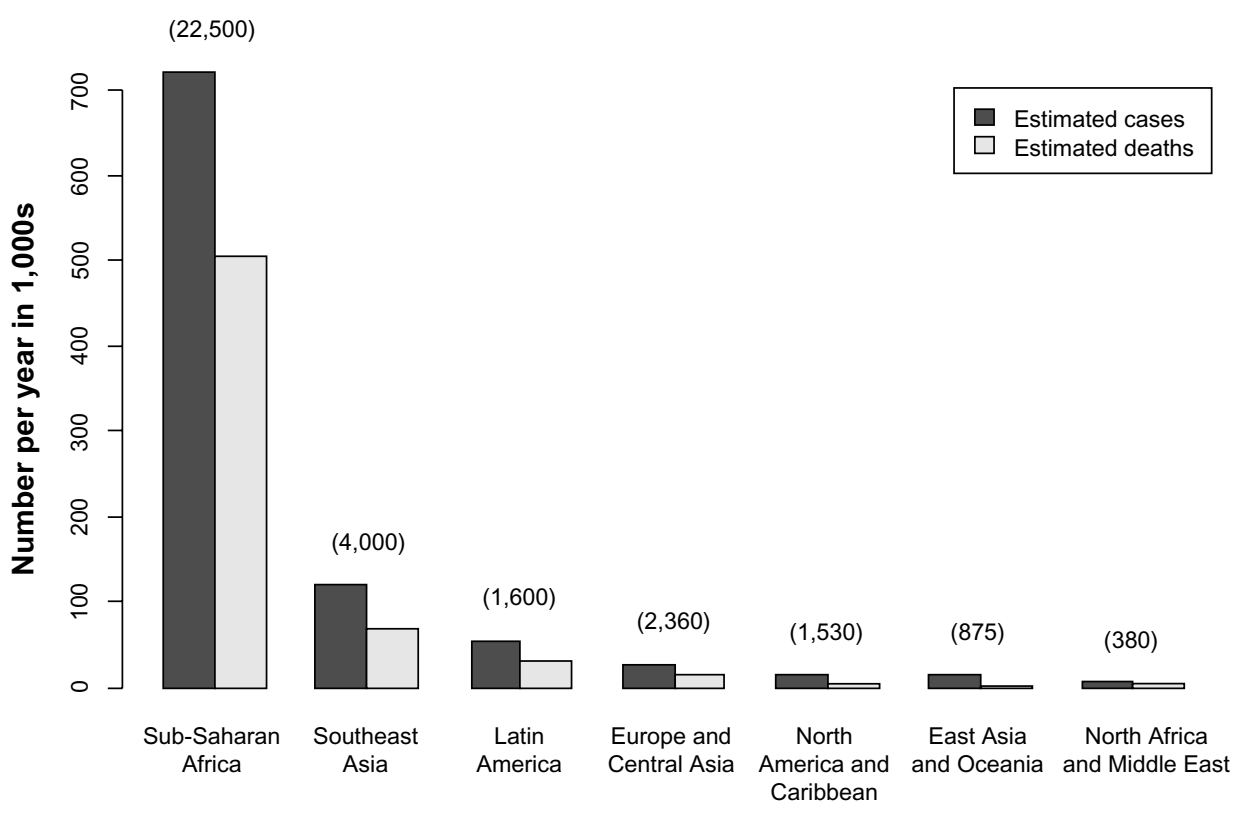

Figure 2 Global incidence and mortality from cryptococcal meningitis among United Nations global regions from 1997 to 2007.

Notes: Figures in brackets and italics indicate human immunodeficiency virus prevalence in I,000s from each region during the period studied. Data from Park et al. ${ }^{3}$

( $27 \%$ of cases), ${ }^{52}$ Zimbabwe ( $45 \%$ of cases), ${ }^{53,54}$ and South Africa (31\% of cases). ${ }^{55}$ Delayed and incomplete access to ART meant that unlike Europe and North America, the incidence of CM did not recede after the turn of the millennium; a tertiary referral hospital in Botswana described C. neoformans growth from $15 \%$ of all cerebrospinal fluid (CSF) samples submitted for analysis in $2003,{ }^{56}$ and a report from Cape Town, South Africa noted that CM still accounted for $31 \%$ of all inpatient days in new ART patients in $2007 .{ }^{57} \mathrm{~A}$ similar persistent elevation of the cryptococcal disease burden since the 1990s has been described from MLICs in Southeast Asia ${ }^{56,58}$ and Latin America. ${ }^{59}$

In addition to disparities in incidence between HICs and MLICs, there are well-documented differences in outcomes (Figure 2). ${ }^{3}$ A combination of earlier access to ART and availability of fungicidal drugs has contributed to falling mortality in $\mathrm{HICs},{ }^{2,60,61}$ while the death rate in MLICs has been relentlessly high. ${ }^{62}$ Analysis of pooled data from case series, surveillance reports, and clinical trials has estimated that the 90-day case-fatality rate from HIV-associated CM in East Asia, Oceania, Western Europe and the US is $9 \%$, compared with $55 \%$ in other parts of Asia and South America and 70\% in sub-Saharan Africa. ${ }^{3}$ Even acknowledging that some North American studies exclude the sickest patients, ${ }^{63}$ and some studies in MLICs show better case-fatality rates than others, ${ }^{64-67}$ these results are unacceptable.

\section{Other risk factors}

Although HIV is the largest driver of cryptococcal disease, it is important to acknowledge other factors. Prior to the HIV era in the UK, the incidence of cryptococcosis per 1,000 persons increased from 1.4 in 1963-1968 to 7.4 in 1973-1978. ${ }^{68}$ This was predominantly attributable to disease in patients on immunosuppressive medications. Use of potent immunosuppressants (eg, corticosteroids, calcineurin inhibitors, ${ }^{69}$ cytotoxic agents, ${ }^{70}$ and monoclonal antibodies ${ }^{71,72}$ ) for transplant conditioning or treatment of cancer and inflammatory conditions has continued to expand in HICs over the last 30 years, sustaining a small but important minority of cryptococcal illness in settings where HIV-related cases are in decline. ${ }^{73}$

Cryptococcosis disease occurs after $2.8 \%-8 \%$ of solidorgan transplants, and is the third-commonest invasive fungal infection in this setting, after Candida and Aspergillus. ${ }^{69,74}$ In a retrospective review of US data from 1996 to 2010, kidney-transplant recipients were most often affected, followed by liver, heart, lung, and pancreas recipients. ${ }^{5}$ The median time to diagnosis after solid-organ transplantation is 20 months, and the etiology is normally reactivation of latent disease. ${ }^{5,74,75}$ Symptoms may emerge sooner after lung or liver transplants, perhaps because the required level of postoperative immunosuppression is higher. ${ }^{69}$ The overall likelihood of cryptococcal disease does not vary between patients using tacrolimus, cyclosporine, or azathioprine as the primary immunosuppressive agent, but patients who 
are coadministered high-dose corticosteroids may be at higher risk. ${ }^{5}$

Infrequently, cryptococcal infection is acquired from donor tissue. This is particularly suspected if disease occurs within 30 days of transplantation, at surgical graft sites, or in multiple organ recipients of a single donor. ${ }^{75-77}$ Screening of donors is not routinely performed, but should be undertaken if the donor has unexplained pulmonary lesions, undiagnosed neurological illness, or unexplained fever with relevant comorbid risk factors. ${ }^{76,77}$

Cryptococcal disease is rare following hematopoietic stem cell transplant or corneal tissue transplant. ${ }^{78}$ Data from a consortium of US transplant centers (Transplant-Associated Infection Surveillance Network) revealed an incidence of only $0.6 \%$ in hematopoietic stem cell-transplant recipients between 2001 and 2006. ${ }^{79,80}$ For unknown reasons, the risk is higher in autologous than allogenic transplants. ${ }^{78}$

Non-HIV-infected, nontransplant recipients with cryptococcosis are a heterogeneous group. Except for C. gattii outbreaks in immunocompetent hosts, most patients have immune dysfunction related to the pathophysiology or treatment of an underlying autoimmune disease, malignancy, or innate immunological disorder. It is difficult to generalize about these cases, but in HICs they tend to experience higher mortality than their HIV-infected counterparts. The reasons for this include the effects of underlying illness and late diagnosis, because the pathogen was not initially suspected..$^{5,73,81}$

\section{Clinical presentation}

Epidemiological variables, including the nature of immunosuppressive risk factors and pathogen species, influence the presentation of cryptococcal disease. CM is the leading presentation overall, ${ }^{19,41,42,78}$ but nonmeningeal manifestations are proportionally more frequent in non-HIV-infected individuals. ${ }^{5,42,73,82}$ Transplant-associated cryptococcosis is often limited to the lungs, ${ }^{83,84}$ with disseminated or neurological disease in $52 \%-61 \%$ of cases. ${ }^{69,84}$

Presentation of $C$. gattii infection in immunocompetent hosts varies according to molecular subtype. In Australia, where the majority of disease is due to VGI, CM is most common, ${ }^{6,85}$ but in North America, VGII disease presents with respiratory symptoms in $76 \%$, neurological symptoms in $7.8 \%$, and both respiratory and neurological symptoms in $10.1 \%$ of cases. ${ }^{19,24,31}$

The commonest features of CM are subacute headache and confusion. Intracranial pressure (ICP) is often elevated, and may cause cranial nerve palsies or seizures. Classical features of "meningism" (eg, neck stiffness) occur in less than $20 \%$ of patients. ${ }^{86}$ Altered mental state is associated with higher mortality. ${ }^{5,50,87}$

Neurological infection may be complicated by mass lesions (cryptococcomas). This is more common with C. gattii than C. neoformans. Clinical sequelae of cryptococcomas include hydrocephalus and blindness. ${ }^{88,89}$ Some patients require neurosurgical intervention. ${ }^{17,18}$

Forty percent of patients with CM have ocular involvement, including papilledema and uveitis with multifocal chorioretinitis. ${ }^{90,91}$ Immune-mediated optic nerve dysfunction and blindness have been particularly reported amongst C. gattii patients from Papua New Guinea. ${ }^{54,89,92}$ The spectrum of pulmonary illness ranges from asymptomatic colonization to severe, progressive pneumonia and cryptococcomas in the lungs. Skin lesions often contain the infecting organism. In severely immunocompromised individuals, disseminated disease (involvement of two or more sites) may present as fever and rash before other symptoms and signs appear.

\section{Investigations}

Confirmation of CM requires lumbar puncture (LP) and examination of CSF, as shown in Figure 3A. Lack of LP equipment may result in underestimation of the disease burden in MLICs. ${ }^{93}$ Typical CSF features include a raised opening pressure (reflecting elevated ICP), lymphocytic pleocytosis, and evidence of inflammation. However, CSF may be normal in $10 \%-17 \%$ of patients, ${ }^{54,94}$ especially in HIV-endemic populations. ${ }^{5}$ Identification of the infecting organism is traditionally done by light microscopy after India ink staining, but this method is user-dependent with variable sensitivity. Detection of cryptococcal antigen $(\mathrm{CrAg})$

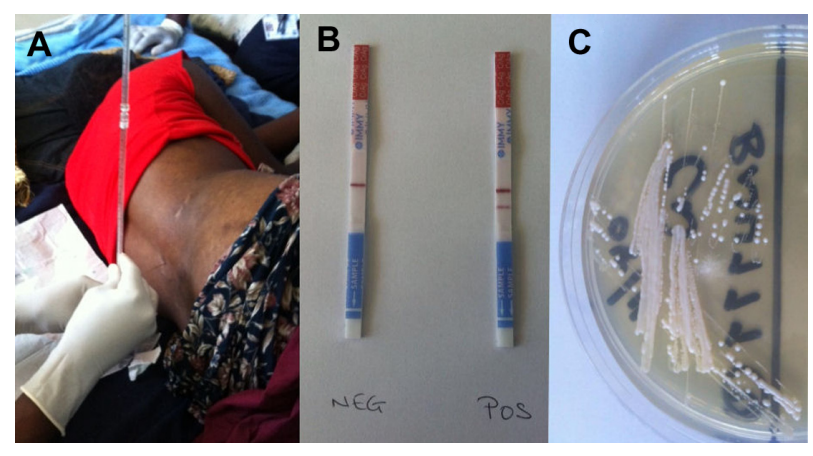

Figure 3 (A-C) Diagnosis of cryptococcal meningitis. (A) Lumbar puncture being performed on a human immunodeficiency virus-infected patient with suspected meningitis in Malawi. (B) Lateral flow immunoassay test strips for cryptococcal antigen detection (the strip on the left shows a negative result, indicated by a single horizontal "control" band in the center; the strip on the right shows a positive result, indicated by adjacent horizontal "control" and "test" bands). (C) Cryptococcus neoformans growing on Sabouraud media. Images kindly supplied by Kate Gaskell, College of Medicine, University of Malawi, and Brigitte Denis, Malawi Liverpool Wellcome Trust Clinical Research Programme. 
by a latex-agglutination test ${ }^{63}$ or lateral flow immunoassay (LFA) is better (Figure 3B). The lateral flow immunoassay is cheaper than latex agglutination, ${ }^{95,96}$ and may be applied to urine samples when CSF is unobtainable. ${ }^{97,98}$ Fungal culture of CSF on Sabouraud media is required to isolate the organism for antimicrobial susceptibility testing. Characteristic colonies grow after 36 hours (Figure 3C).

Radiology has little role in the diagnosis of CM, but computed tomography and magnetic resonance imaging scans are necessary to detect complications (eg, cryptococcomas and noncommunicating hydrocephalus). These modalities are generally unavailable in MLICs.

Nonmeningeal cryptococcosis may be confirmed by tissue sampling for microbiological analysis. Cryptococcemia is identified from fungal blood cultures or $\mathrm{CrAg}$ detection in serum samples. Asymptomatic antigenemia (a positive serum $\mathrm{CrAg}$ in the absence of clinical disease) has been described in HIV-infected patients, and may predict impending CM. Screening and treatment for asymptomatic antigenemia will be discussed later.

\section{Treatment and prognosis}

The Infectious Diseases Society of America (IDSA) ${ }^{4}$ and World Health Organization (WHO) ${ }^{99}$ have recently issued updated treatment guidelines to reflect advances over the last decade, but routine practice in MLICs continues to be impeded by poor drug availability. Figure 4 summarizes current recommendations.

\section{Induction and consolidation antifungal therapy for HIV-associated CM}

CM treatment consists of three phases: induction, consolidation, and maintenance. IDSA and WHO guidelines emphasize the importance of potent fungicidal drugs during induction therapy, because the rate of fungal clearance from the CSF during the first 2 weeks, known as early fungicidal activity (EFA),${ }^{100}$ predicts 10 -week survival, ${ }^{101}$ and CSF sterilization by 14 days predicts long-term prognosis. ${ }^{63}$

Amphotericin B (AmB), the drug with the greatest EFA, is administered intravenously for 14 days during induction therapy whenever possible. Its activity is concentrationdependent, ${ }^{102}$ but the required dose $(0.7-1.0 \mathrm{mg} / \mathrm{kg})$ of the commonest preparation (AmB deoxycholate $[\mathrm{AmBd}])^{33,63-65}$ can be nephrotoxic. ${ }^{103,104} \mathrm{~A}$ solution in HICs is the use of lipid drug formulations with fewer renal side effects, including liposomal AmB (LAmB; 3-6 mg/kg/day) and AmB lipid complex (ABLC, $5 \mathrm{mg} / \mathrm{kg} /$ day). ${ }^{105-107}$ The cost of these (over US $\$ 1,000$ per day ${ }^{108}$ ) is prohibitive for MLICs, so alternative strategies, including preemptive hydration and electrolyte supplementation, have been developed to minimize the toxicity of AmBd. ${ }^{99}$ Studies in Kampala, ${ }^{62}$ Cape Town, ${ }^{65}$ and Bangkok ${ }^{109}$ support this approach.

Even a 2-week course of AmBd (US\$12-\$15 per day) is too expensive for some LICs. ${ }^{110}$ In this scenario, data from South Africa and Malawi have demonstrated that 5-7 days of $\mathrm{AmBd}$ is better than treatment that is restricted to less fungicidal drugs. ${ }^{64,111}$ AmBd-treated patients who survive the first 6 months have a subsequent 5-year survival rate of $88 \%$. $^{12}$ This advocates for investment in early AmBd to achieve satisfactory long-term outcomes.

Flucytosine should accompany AmB during induction therapy at an intravenous or oral dose of $100 \mathrm{mg} / \mathrm{kg} / \mathrm{day} .^{100,113-115}$ Omission of this agent has been associated with higher rates of mortality, ${ }^{113}$ treatment failure, ${ }^{116}$ and late relapse. ${ }^{117}$ Toxic cytopenias can occur during flucytosine therapy, and so regular full blood counts and therapeutic drug monitoring (TDM) are advised by IDSA guidelines., ${ }^{47,118}$ TDM is arduous, and the absolute need for it in MLICs was questioned by a recent study in Vietnam that did not use TDM but demonstrated safe and effective use of AmBd-flucytosine. ${ }^{113}$

Despite its value, flucytosine remains unlicensed in most African and Asian countries, ${ }^{114,119,120}$ so alternative agents have been considered for combination with AmB. The obvious contender is fluconazole, which is freely distributed in MLICs (http://www.pfizer.com/responsibility/global health/ diflucan partnership program), but is fungistatic rather than fungicidal in the normal human dose range. Definitive evidence to support AmB-fluconazole induction therapy is lacking, but reports from several countries describe rapid EFA when intravenous $\mathrm{AmBd}(0.7-1 \mathrm{mg} / \mathrm{kg} /$ day) is prescribed alongside oral fluconazole (800-1,200 mg/day). ${ }^{109,113,121,122}$ A meta-analysis of various induction strategies in resourcepoor settings has described AmBd-fluconazole as costeffective. ${ }^{123}$ The WHO recommends this approach when flucytosine cannot be obtained..$^{99}$

After a 14-day induction phase, treatment proceeds with a consolidation phase of $400 \mathrm{mg}$ once daily (od) for a further 8 weeks. This dose may be increased to $800 \mathrm{mg}$ when gold-standard induction therapy with AmB-flucytosine is unavailable.

Gaps in drug provision leave fluconazole as the only agent for induction and consolidation therapy in many high-burden countries, contributing to significant variation in prognosis. The response to this requires discussion. Until recently, the routine dose of fluconazole for $\mathrm{CM}$ monotherapy was $200-400 \mathrm{mg}$ od, and 8-week mortality was $78 \%-90 \%{ }^{86,124} \mathrm{In}$ 


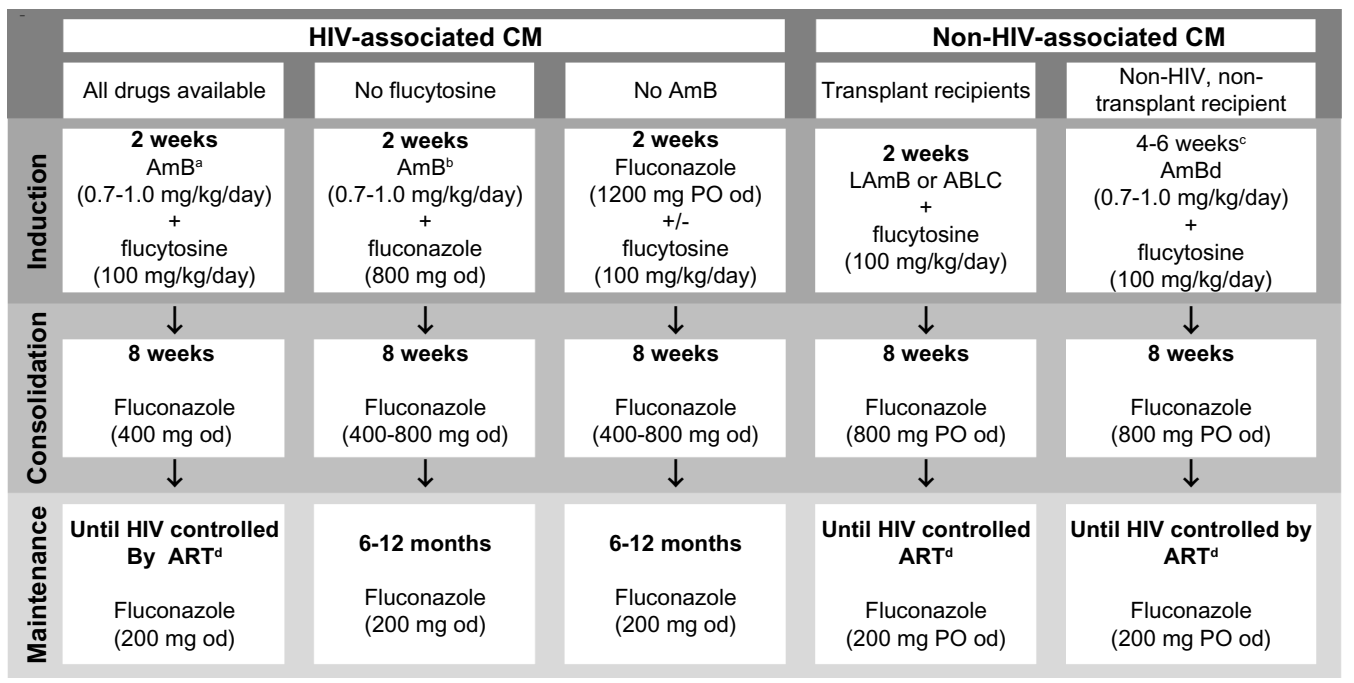

Figure 4 Treatment options for cryptococcal meningitis (CM), summarized from Infectious Diseases Society of America and World Health Organization guidelines. Notes: an HIV-infected patients with renal impairment or concern about nephrotoxicity, LAmB or ABLC should be used. bln settings of limited AmB availability or difficulty with toxicity monitoring, an abbreviated 5- to 7-day induction course of AmB may be used. cNon-HIV, nontransplant patients are a heterogeneous group, including individuals with hematological malignancies and immunocompetent hosts with Cryptococcus gattii infection. There is no consensus on optimal treatment; some authors suggest identical induction and consolidation therapy as for HIV-associated CM. dUndetectable HIV viral load and CD4 > I00/ $\mu \mathrm{L}$ should be demonstrated on two occasions 6 months apart before stopping fluconazole.

Abbreviations: HIV, human immunodeficiency virus; AmB, amphotericin B; LAmB, liposomal amphotericin B (3-6 mg/kg/day); ABLC, amphotericin B lipid complex (5 mg/kg/day); od, once daily; PO, per os (by mouth); ART, antiretroviral therapy.

one South African study from 2006, median patient survival on induction- and consolidation-phase fluconazole (400 mg od) was only 76 days. ${ }^{125}$

Such poor outcomes prompted dose escalation. Clinical studies in Uganda and Malawi based on $800 \mathrm{mg}$ od induction and $400 \mathrm{mg}$ od consolidation therapy reported improved 10 -week mortality rates of $58 \%-60 \%{ }^{87,126}$ A further induction-phase dose increase to $1,200 \mathrm{mg}$ was associated with faster EFA ${ }^{126}$ but did not improve survival, ${ }^{126,127}$ and a pharmacokinetic-pharmacodynamic bridging study from a mouse model indicated that 1,200 mg od will fail to achieve fungal stasis in the CSF of $33 \%$ of patients. ${ }^{128}$ An exploratory clinical trial has suggested that induction with 1,600-2,000 $\mathrm{mg}$ of fluconazole would be more efficacious, ${ }^{126,129}$ but additional evaluation of these doses is required. WHO guidelines currently advocate that where fluconazole monotherapy is the only option, $1,200 \mathrm{mg}$ od should be used for 2-week induction therapy followed by a consolidation phase of $800 \mathrm{mg}$ od for 8 weeks. ${ }^{99}$

A final option when intravenous drug administration is not feasible is a fully oral induction phase of fluconazole and flucytosine. Trials in Malawi have confirmed that fluconazole $(1,200 \mathrm{mg}$ od $)$ and flucytosine $(100 \mathrm{mg} / \mathrm{kg} /$ day $)$ achieve faster EFA and lower 10-week mortality than fluconazole alone, ${ }^{70,111,127}$ suggesting that fluconazole monotherapy should be augmented by induction-phase flucytosine wherever possible.

Overall, reduced availability of fungicidal drugs continues to compromise outcomes in high-burden countries. An ongoing multicenter clinical trial (Advancing Cryptococcal meningitis Treatment in Africa [ACTA] ${ }^{130}$ ) in sub-Saharan Africa hopes to confirm the shortest, simplest effective regimens, but will require backup by universal provision of medicines for routine care.

\section{Maintenance antifungal therapy for HIV-associated CM}

After consolidation therapy, secondary prophylaxis with fluconazole ( $200 \mathrm{mg}$ od) minimizes the risk of CM relapse. ${ }^{131}$ Alternative, less effective maintenance regimens include oral itraconazole (200 mg od) $)^{117}$ and intravenous AmBd (1 mg/kg/once weekly). ${ }^{132}$

The required duration of maintenance therapy has recently been examined, particularly as the 1-year default rate from secondary prophylaxis in some African settings exceeds $90 \% .{ }^{133,134}$ In the pre-ART era, lifelong fluconazole was recommended after a presentation with $\mathrm{CM}$, but it now appears that late relapse is unlikely during successful ART. ${ }^{135-138}$ International guidelines state that immune restoration by ART permits discontinuation of maintenance therapy (Figure 4). However, evidence to support cessation of 
secondary prophylaxis is weaker when induction/consolidation therapy is not fungicidal (eg, fluconazole monotherapy), and isolated CM relapses have been described in patients on ART with CD4 counts up to 495 cells/ $\mu \mathrm{L} .^{139}$

\section{Differences in antifungal therapy for non-HIV-associated CM}

Treatment of non-HIV-associated CM varies from that described above, dependent on characteristics of the host and pathogen (Figure 4). Patients developing CM after solid-organ transplant often take nephrotoxic immunosuppressants (tacrolimus, cyclosporine or sirolimus) to prevent graft rejection, and $25 \%$ of transplant recipients have renal dysfunction at $\mathrm{CM}$ diagnosis. Therefore, kidney-friendly liposomal preparations of $\mathrm{AmB}$ (eg, LAmB or ABLC) are recommended during induction therapy. ${ }^{4}$ It is uncertain whether immunosuppressive therapy should be stopped during CM treatment; this may accelerate eradication of the pathogen, but poses a risk of proinflammatory immune reconstitution syndrome or transplant rejection. ${ }^{140}$ Although clear evidence is lacking, some authors report good outcomes with a staged reduction in immunosuppressive therapy alongside antifungal drugs. ${ }^{141}$

Secondary fluconazole prophylaxis in transplant recipients may stop after 6-12 months, as the late cryptococcal relapse rate is only $1 \%-3 \% .{ }^{142}$ There is no standard regimen for non-HIV, nontransplant patients with $\mathrm{CM}$. Some authors advocate a longer (4-6 weeks) induction phase of AmB/ flucytosine (Figure 4), while others favor a standard 2-week induction phase. Consolidation and maintenance therapy are identical to transplant recipients. $C$. gattii infection should be treated with the same drugs as $C$. neoformans, but the response to therapy may be slower, due to higher azole minimum inhibitory concentrations ${ }^{143,144}$ and poor drug penetration of cryptococcomas..$^{17,18,85}$

\section{Asymptomatic antigenemia and primary prophylaxis}

Between $4 \%$ and $20 \%$ of patients with newly identified HIV infection and a CD4 count $<150$ cells/ $\mu \mathrm{L}$ have a positive serum $\mathrm{CrAg}$ test in the absence of clinical cryptococcosis. ${ }^{145-147}$ Asymptomatic antigenemia predicts impending $\mathrm{CM},{ }^{148}$ and is associated with increased mortality. ${ }^{149}$ Serum CrAg screening of new HIV patients is being implemented in South Africa, ${ }^{150}$ prompting debate on the use of preemptive therapy for those at highest risk.

Treatment of asymptomatic antigenemia is not recommended in $\mathrm{HICs},{ }^{4}$ but some studies support fluconazole therapy for serum CrAg-positive patients in MLICs. ${ }^{151-153}$ A management algorithm is shown in Figure 5. ${ }^{154}$ However, deployment of preventive screening and therapy strategies is operationally difficult, and an implementation study in Kenya achieved effective fluconazole administration for only $52 \%$ of eligible patients. ${ }^{155}$ The benefit of presumptive therapy for asymptomatic antigenemia will depend on the logistics of integrating this strategy into routine practice at ART clinics.

An alternative means of CM prevention is primary prophylaxis with fluconazole for all patients with CD4 counts $<100$ cells $/ \mu \mathrm{L}$, irrespective of serum CrAg testing. Studies of this approach in Thailand ${ }^{156}$ and Uganda ${ }^{157}$ demonstrated that fluconazole $200 \mathrm{mg}$ once daily reduced the incidence of CM, but there was no reduction in overall mortality and rates of fluconazole-resistant Candida albicans infection increased. ${ }^{158}$ The cost-effectiveness of no preventive treatment, therapy for asymptomatic antigenemia, or primary prophylaxis is likely to vary between regions, based on the underlying epidemiology of cryptococcal infection and availability of ART.

\section{Additional therapeutic considerations}

Outcomes from CM may be improved by reduction of raised ICP during early therapy, careful management of immune reconstitution inflammatory syndrome (IRIS) and appropriately timed ART initiation for HIV-infected patients.

\section{Reducing raised intracranial pressure}

Increased ICP $\left(>25 \mathrm{~cm} / \mathrm{H}_{2} \mathrm{O}\right)$ is associated with greater CSF fungal burden ${ }^{159}$ and higher mortality. ${ }^{160}$ Regular CSF drainage by serial LPs is recommended. ${ }^{115,161-164}$ Insertion of a temporary CSF-drainage catheter ${ }^{165}$ or ventriculoperitoneal shunt may also be used. ${ }^{166}$ Drug therapy (eg, acetazolamide or corticosteroids) to reduce CSF pressure or prevent blindness in $\mathrm{CM}$ patients is not beneficial, and acetazolamide may cause harm. ${ }^{88,160,167}$

\section{Managing immune reconstitution inflammatory syndromes}

IRIS in CM patients occurs when host immune recovery triggers inflammatory reactions to persistent fungal antigens. There are two main forms: unmasking and paradoxical (Figure 6). ${ }^{168}$

Unmasking IRIS occurs in HIV-infected patients when subclinical cryptococcal disease emerges after ART is commenced. This might be prevented by careful pre-ART screening. However, late ART is generally associated with 


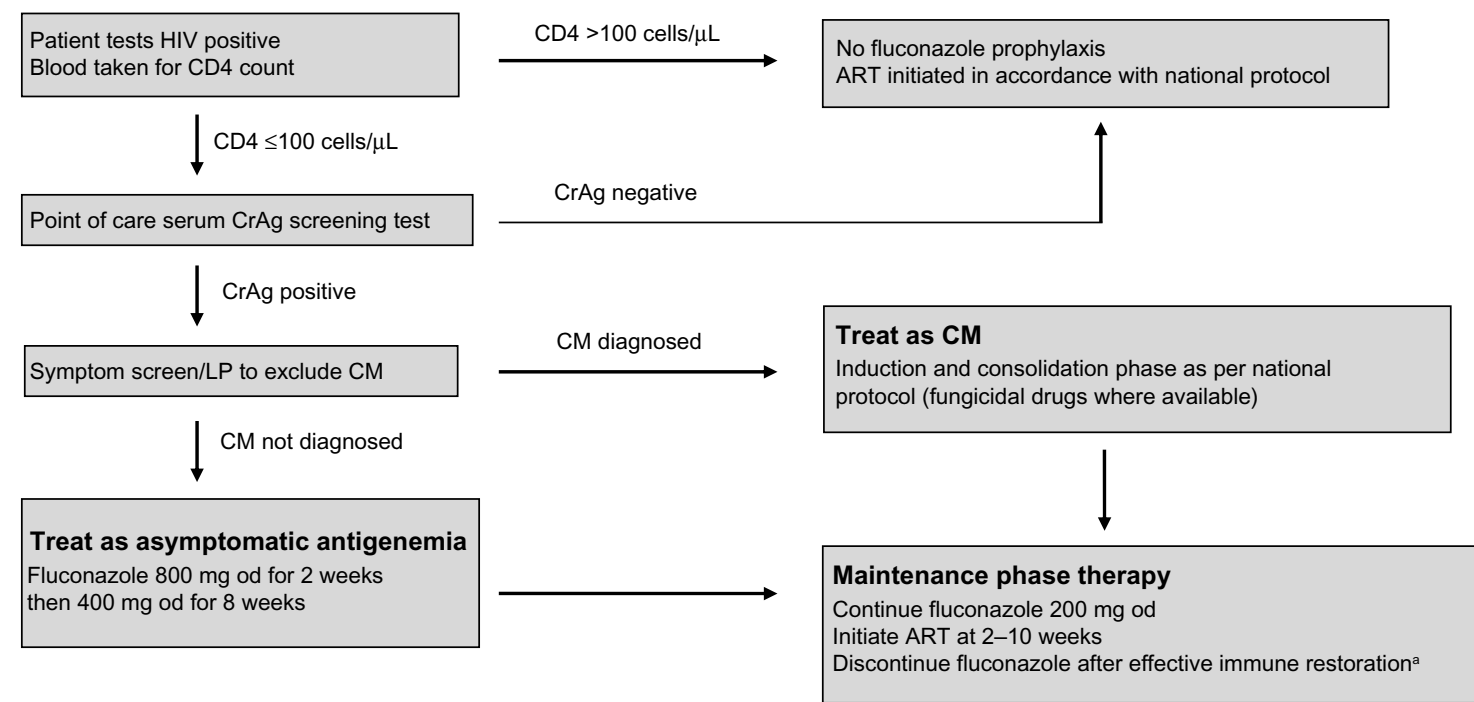

Figure 5 A screening and management strategy for asymptomatic antigenemia.

Notes: ${ }^{a}$ Undetectable HIV viral load and CD4 >100/ $\mu \mathrm{L}$ should be demonstrated on two occasions 6 months apart before stopping fluconazole. Jarvis JN, Govender N, Chiller T, et al, J Int Assoc Physicians AIDS Care (Chic) (II), pP 374-379, copyright ( 2012 by SAGE Publications. Adapted by permission of SAGE Publications. ${ }^{154}$

Abbreviations: HIV, human immunodeficiency virus; $\mathrm{CrAg}$, cryptococcal antigen; LP, lumbar puncture; CM, cryptococcal meningitis; od, once daily; ART, antiretroviral therapy.

lower survival, ${ }^{169}$ and patients who are already on HIV therapy when they present with CM tend to have better outcomes, ${ }^{64,170}$ so excessive delays should be avoided.

Paradoxical IRIS is best described in HIV-associated CM patients who initially respond to antifungal drugs and then deteriorate within 12 months of starting ART. Studies from South Africa and Ethiopia estimate an incidence of 7\%-33\%. ${ }^{171-173}$ Paradoxical IRIS also affects solid organtransplant patients when antirejection medications are interrupted during CM therapy, ${ }^{141}$ and apparently healthy hosts may suffer from reactivation of immune defenses that were previously overwhelmed by high fungal burden.
Paradoxical IRIS in the central nervous system has a mortality of up to $36 \%{ }^{174,175}$ Risk factors include severe disease at presentation and slow fungal elimination. ${ }^{176,177}$ The benefit of anti-inflammatory drugs (eg, corticosteroids ${ }^{100}$ ) is unproven. ${ }^{178}$ Highly fungicidal induction-phase therapy and rapid CSF sterilization is the best way to minimize unwanted reactions. ${ }^{179,180}$

\section{Combining anticryptococcal and anti-HIV medications}

In HIV-associated CM, IRIS is more likely during immune reconstitution from lower baseline CD4 counts, and is

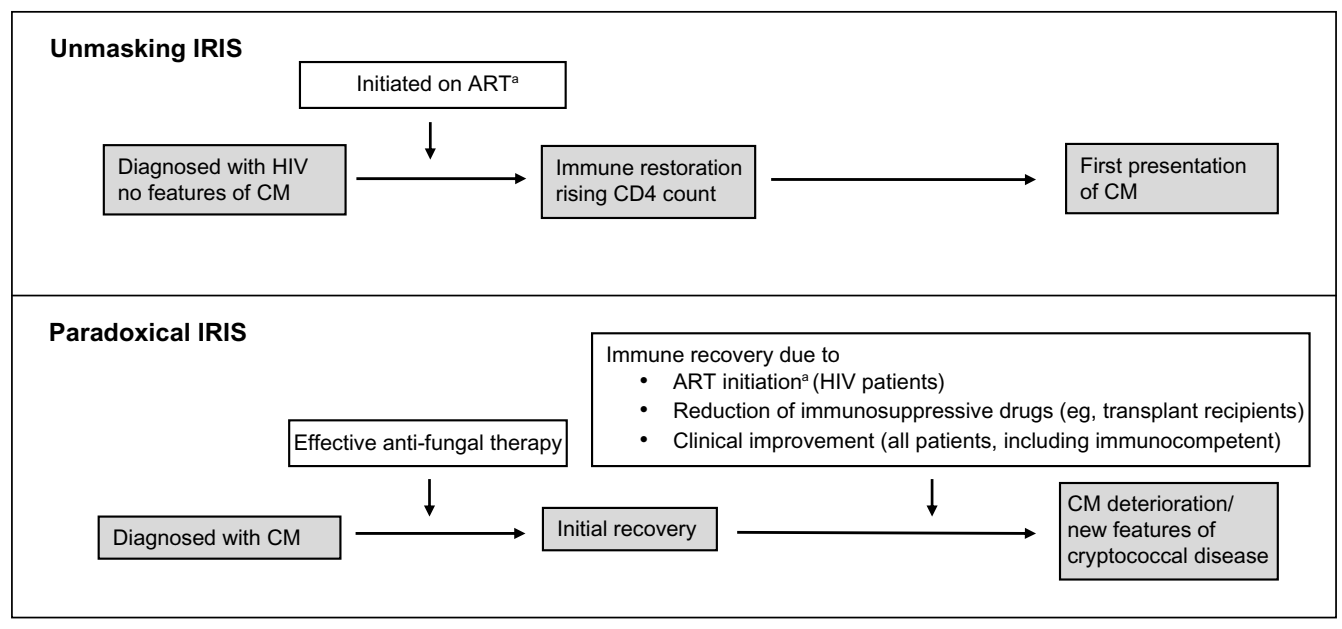

Figure 6 Types of immune restoration inflammatory syndrome (IRIS) in cryptococcal disease.

Note: aHIV-associated CM IRIS should occur within 12 months of ART initiation.

Abbreviations: ART, antiretroviral therapy; HIV, human immunodeficiency virus; CM, cryptococcal meningitis. 
Table I Prospective open-label randomized trials to assess optimal timing of antiretroviral therapy (ART) initiation in human immunodeficiency virus (HIV)-infected patients with cryptococcal meningitis (CM)

\begin{tabular}{|c|c|c|c|c|c|}
\hline Study and site & Study design & $\begin{array}{l}\text { Baseline CD4 } \\
\text { count, cells } / \mu \mathrm{L} \text {, } \\
\text { median (IQR) }\end{array}$ & $\begin{array}{l}\text { CM induction- } \\
\text { phase drugs }\end{array}$ & $\begin{array}{l}\text { Initiation of } \\
\text { ART during } \\
\text { CM therapy }\end{array}$ & Study outcomes \\
\hline $\begin{array}{l}\text { Zolopa et al, }{ }^{182} \\
\text { USA }{ }^{a} \text { and } \\
\text { South Africa }\end{array}$ & $\begin{array}{l}282 \text { patients with } \\
\text { Ols ( } 35 \text { with } \mathrm{CM}) \\
\text { 48-week follow-up }\end{array}$ & $29(10-55)$ & Not stated & $\begin{array}{l}<2 \text { weeks versus } \\
4-32 \text { weeks }\end{array}$ & $\begin{array}{l}\text { All patients: fewer AIDS events/ } \\
\text { deaths in early ( } 20 \text { of I } 4 \text { I [I4\%]) } \\
\text { versus late ( } 34 \text { of I4I [24\%]) ART } \\
\text { (OR } 0.5,95 \% \mathrm{Cl} 0.3-0.9) \\
\text { CM patients: no difference in } \\
\text { AIDS events/deaths in early } \\
\text { (one of I3 [8\%]) versus late (three } \\
\text { of } 22 \text { [I4\%]) ART (OR } 0.5,96 \% \\
\mathrm{Cl} 0.1-5.7 \text { ) }\end{array}$ \\
\hline $\begin{array}{l}\text { Makadzange et al, }{ }^{184} \\
\text { Zimbabwe }\end{array}$ & $\begin{array}{l}54 \text { patients with CM } \\
\text { 3-year follow-up }\end{array}$ & $37(17-69)$ & Fluconazole only & $\begin{array}{l}<72 \text { hours versus } \\
>10 \text { weeks }\end{array}$ & $\begin{array}{l}\text { Higher mortality in early ( } 23 \text { of } 28 \\
\text { [82\%]) versus late (I } 2 \text { of } 26 \text { [46\%]) } \\
\text { ART (HR } 2.3,95 \% \text { Cl I.I-4.9) }\end{array}$ \\
\hline $\begin{array}{l}\text { Bisson et al, }{ }^{183} \\
\text { Botswana }\end{array}$ & $\begin{array}{l}27 \text { patients with CM } \\
24 \text {-week follow-up }\end{array}$ & $29(11-50)$ & AmB + fluconazole & $\begin{array}{l}<7 \text { days versus } \\
>28 \text { days }\end{array}$ & $\begin{array}{l}\text { No difference in mortality in early } \\
\text { (two of I3 [I5\%]) versus late (five } \\
\text { of I4 [36\%]) ART (OR 0.3, 95\% } \\
\mathrm{Cl} 0.1-2.1 \text { ) }\end{array}$ \\
\hline $\begin{array}{l}\text { Boulware et al, }{ }^{185} \\
\text { Uganda and } \\
\text { South Africa }\end{array}$ & $\begin{array}{l}\text { I77 patients with CM } \\
\text { 6-month follow-up }\end{array}$ & $19(9-69)$ & AmB + flucytosine & $\begin{array}{l}<14 \text { days versus } \\
>28 \text { days }\end{array}$ & $\begin{array}{l}\text { Higher mortality in early } \\
(40 / 88[45 \%]) \text { versus late }(27 \text { of } \\
89[30 \%]) \text { ART (HR I.7, } 95 \% \mathrm{Cl} \\
\text { I.I-2.8; P=0.03) }\end{array}$ \\
\hline
\end{tabular}

Note: ancludes patients from Puerto Rico.

Abbreviations: IQR, interquartile range; AIDS, acquired immunodeficiency syndrome; OR, odds ratio; HR, hazard ratio; Cl, confidence interval AmB, amphotericin B; Ols, opportunistic infections.

influenced by the timing of ART introduction. Balancing the danger of early mortality from advanced immunosuppression against that of accelerated immune recovery is difficult, and best practice remains to be established. A retrospective study of mortality after ART initiation in Thailand at time points 1-12 months into CM therapy did not show any association between timing of ART and outcome. ${ }^{181}$ Table 1 summarizes subsequent prospective trials. ${ }^{135,136,182-185}$ The most convincing data come from a recent study in Uganda and South Africa, which was terminated early because ART initiation within the first 28 days of CM treatment led to a higher risk of IRIS and death. ${ }^{185}$ Introduction of ART 4-10 weeks after starting antifungal treatment is currently considered the safest approach.

\section{Conclusion}

Advanced HIV infection continues to drive cryptococcal disease worldwide. Patients on immunosuppressive drugs and some immunocompetent hosts are also at risk. Although treatment with potent drug combinations provides effective cure, poor availability of fungicidal drugs in MLICs results in high case-fatality rates. Expanded provision of fungicidal treatment is urgently required. Ongoing research on management of asymptomatic antigenemia and optimal timing of ART initiation is important to improve the prognosis of HIV-associated CM.

\section{Disclosure}

The authors report no conflicts of interest in this work.

\section{References}

1. Leal AL, Faganello J, Fuentefria AM, Boldo JT, Bassanesi MC, Vainstein MH. Epidemiological profile of cryptococcal meningitis patients in Rio Grande do Sul, Brazil. Mycopathologia. 2008;166: 71-75.

2. Pyrgos V, Seitz AE, Steiner CA, Prevots DR, Williamson PR. Epidemiology of cryptococcal meningitis in the US: 1997-2009. PLoS One. 2013;8:e56269.

3. Park BJ, Wannemuehler KA, Marston BJ, Govender N, Pappas PG, Chiller TM. Estimation of the current global burden of cryptococcal meningitis among persons living with HIV/AIDS. AIDS 2009;23:525-530.

4. Perfect JR, Dismukes WE, Dromer F, et al. Clinical practice guidelines for the management of cryptococcal disease: 2010 update by the Infectious Diseases Society of America. Clin Infect Dis. 2010;50:291-322.

5. Brizendine KD, Baddley JW, Pappas PG. Predictors of mortality and differences in clinical features among patients with cryptococcosis according to immune status. PLoS One. 2013;8:e60431.

6. Byrnes EJ 3rd, Bartlett KH, Perfect JR, Heitman J. Cryptococcus gattii: an emerging fungal pathogen infecting humans and animals. Microbes Infect. 2011;13:895-907.

7. Sanfelice F. Sull'azione patogena dei bastomiceti [On the action of pathogenic bastomiceti]. Ann Isto Igiene R Univ Roma. 1895;5:239-262. Italian. 
8. Sanfelice F. Contributo alle morfologia e biologia dei blastomiceti che si sviluppano nei succhi di alcuni frutti [Contribution to the morphology and biology of blastomiceti developing in some fruit juices]. Ann Isto Igiene R Univ Roma. 1894;4:463-495. Italian.

9. Franzot SP, Salkin IF, Casadevall A. Cryptococcus neoformans var. grubii: separate varietal status for Cryptococcus neoformans serotype A isolates. J Clin Microbiol. 1999;37:838-840.

10. Dromer F, Mathoulin S, Dupont B, Letenneur L, Ronin O. Individual and environmental factors associated with infection due to Cryptococcus neoformans serotype D. French Cryptococcosis Study Group. Clin Infect Dis. 1996;23:91-96.

11. Tortorano AM, Viviani MA, Rigoni AL, Cogliati M, Roverselli A, Pagano A. Prevalence of serotype D in Cryptococcus neoformans isolates from HIV positive and HIV negative patients in Italy. Mycoses. 1997;40:297-302.

12. Antinori S. New Insights into HIV/AIDS-associated cryptococcosis. ISRN AIDS. 2013;2013:471363.

13. Kwon-Chung KJ, Bennett JE. Epidemiologic differences between the two varieties of Cryptococcus neoformans. Am J Epidemiol. 1984;120:123-130.

14. Pappas PG, Perfect JR, Cloud GA, et al. Cryptococcosis in human immunodeficiency virus-negative patients in the era of effective azole therapy. Clin Infect Dis. 2001;33:690-699.

15. Lui G, Lee N, Ip M, et al. Cryptococcosis in apparently immunocompetent patients. QJM. 2006;99:143-151.

16. Velagapudi R, Hsueh YP, Geunes-Boyer S, Wright JR, Heitman J. Spores as infectious propagules of Cryptococcus neoformans. Infect Immun. 2009; 77:4345-4355.

17. Mitchell DH, Sorrell TC, Allworth AM, et al. Cryptococcal disease of the CNS in immunocompetent hosts: influence of cryptococcal variety on clinical manifestations and outcome. Clin Infect Dis. 1995;20:611-616.

18. Speed B, Dunt D. Clinical and host differences between infections with the two varieties of Cryptococcus neoformans. Clin Infect Dis. 1995;21:28-34; discussion 5-6.

19. Chen SC, Slavin MA, Heath $\mathrm{CH}$, et al. Clinical manifestations of Cryptococcus gattii infection: determinants of neurological sequelae and death. Clin Infect Dis. 2012;55:789-798.

20. Sukroongreung S, Nilakul C, Ruangsomboon O, Chuakul W, Eampokalap B. Serotypes of Cryptococcus neoformans isolated from patients prior to and during the AIDS era in Thailand. Mycopathologia. 1996;135:75-78.

21. Fisher D, Burrow J, Lo D, Currie B. Cryptococcus neoformans in tropical northern Australia: predominantly variant gattii with good outcomes. Aust N Z J Med. 1993;23:678-682.

22. Ellis DH. Cryptococcus neoformans var. gattii in Australia. J Clin Microbiol. 1987;25:430-431.

23. Seaton RA. The management of cryptococcal meningitis in Papua New Guinea. P N G Med J. 1996;39:67-73.

24. Seaton RA, Hamilton AJ, Hay RJ, Warrell DA. Exposure to Cryptococcus neoformans var. gattii - a seroepidemiological study. Trans R Soc Trop Med Hyg. 1996;90:508-512.

25. Laurenson IF, Lalloo DG, Naraqi S, et al. Cryptococcus neoformans in Papua New Guinea: a common pathogen but an elusive source. $J$ Med Vet Mycol. 1997;35:437-440.

26. Laurenson IF, Trevett AJ, Lalloo DG, et al. Meningitis caused by Cryptococcus neoformans var. gattii and var. neoformans in Papua New Guinea. Trans R Soc Trop Med Hyg. 1996;90:57-60.

27. Kidd SE, Hagen F, Tscharke RL, et al. A rare genotype of Cryptococcus gattii caused the cryptococcosis outbreak on Vancouver Island (British Columbia, Canada). Proc Natl Acad Sci U S A. 2004;101: 17258-17263.

28. Fraser JA, Giles SS, Wenink EC, et al. Same-sex mating and the origin of the Vancouver Island Cryptococcus gattii outbreak. Nature. 2005;437:1360-1364.

29. Datta K, Bartlett KH, Baer R, et al. Spread of Cryptococcus gattii into Pacific Northwest region of the United States. Emerg Infect Dis. 2009;15:1185-1191.
30. Centers for Disease Control and Prevention. Emergence of Cryptococcus gattii - Pacific Northwest, 2004-2010. MMWR Morb Mortal Wkly Rep. 2010;59:865-868.

31. Bartlett KH, Cheng PY, Duncan C, et al. A decade of experience: Cryptococcus gattii in British Columbia. Mycopathologia. 2012;173: 311-319.

32. Upton A, Fraser JA, Kidd SE, et al. First contemporary case of human infection with Cryptococcus gattii in Puget Sound: evidence for spread of the Vancouver Island outbreak. J Clin Microbiol. 2007;45:3086-3088.

33. Brandt ME, Hutwagner LC, Klug LA, et al. Molecular subtype distribution of Cryptococcus neoformans in four areas of the United States. Cryptococcal Disease Active Surveillance Group. J Clin Microbiol. 1996;34:912-917.

34. Karstaedt AS, Crewe-Brown HH, Dromer F. Cryptococcal meningitis caused by Cryptococcus neoformans var. gattii, serotype C, in AIDS patients in Soweto, South Africa. Med Mycol. 2002;40:7-11.

35. McCarthy KM, Morgan J, Wannemuehler KA, et al. Population-based surveillance for cryptococcosis in an antiretroviral-naive South African province with a high HIV seroprevalence. AIDS. 2006;20:2199-2206.

36. Steele KT, Thakur R, Nthobatsang R, Steenhoff AP, Bisson GP. In-hospital mortality of HIV-infected cryptococcal meningitis patients with C. gattii and C. neoformans infection in Gaborone, Botswana. Med Mycol. 2010;48:1112-1115.

37. Litvintseva AP, Thakur R, Reller LB, Mitchell TG. Prevalence of clinical isolates of Cryptococcus gattii serotype $\mathrm{C}$ among patients with AIDS in sub-Saharan Africa. J Infect Dis. 2005;192:888-892.

38. Pfeiffer TJ, Ellis DH. Environmental isolation of Cryptococcus neoformans var. gattii from Eucalyptus tereticornis. J Med Vet Mycol. 1992;30:407-408.

39. Bartlett KH, Kidd SE, Kronstad JW. The emergence of Cryptococcus gattii in British Columbia and the Pacific Northwest. Curr Infect Dis Rep. 2008;10:58-65.

40. MacDougall L, Kidd SE, Galanis E, et al. Spread of Cryptococcus gattii in British Columbia, Canada, and detection in the Pacific Northwest, USA. Emerg Infect Dis. 2007;13:42-50.

41. Dromer F, Mathoulin-Pelissier S, Fontanet A, Ronin O, Dupont B, Lortholary O. Epidemiology of HIV-associated cryptococcosis in France (1985-2001): comparison of the pre- and post-HAART eras. AIDS. 2004;18:555-562.

42. Knight FR, Mackenzie DW, Evans BG, Porter K, Barrett NJ, White GC. Increasing incidence of cryptococcosis in the United Kingdom. J Infect. 1993;27:185-191.

43. Currie BP, Casadevall A. Estimation of the prevalence of cryptococcal infection among patients infected with the human immunodeficiency virus in New York City. Clin Infect Dis. 1994;19:1029-1033.

44. Jarvis JN, Harrison TS. HIV-associated cryptococcal meningitis. AIDS. 2007;21:2119-2129.

45. Kisenge PR, Hawkins AT, Maro VP, et al. Low CD4 count plus coma predicts cryptococcal meningitis in Tanzania. BMC Infect Dis. 2007;7:39.

46. van Elden LJ, Walenkamp AM, Lipovsky MM, et al. Declining number of patients with cryptococcosis in the Netherlands in the era of highly active antiretroviral therapy. AIDS. 2000;14:2787-2788.

47. Mocroft A, Vella S, Benfield TL, et al. Changing patterns of mortality across Europe in patients infected with HIV-1. EuroSIDA Study Group. Lancet. 1998;352:1725-1730.

48. Palella FJ Jr, Delaney KM, Moorman AC, et al. Declining morbidity and mortality among patients with advanced human immunodeficiency virus infection. HIV Outpatient Study Investigators. $N$ Engl J Med. 1998;338:853-860.

49. Garvey L, Winston A, Walsh J, et al. HIV-associated central nervous system diseases in the recent combination antiretroviral therapy era. Eur J Neurol. 2011;18:527-534.

50. Mirza SA, Phelan M, Rimland D, et al. The changing epidemiology of cryptococcosis: an update from population-based active surveillance in 2 large metropolitan areas, 1992-2000. Clin Infect Dis. 2003;36:789-794. 
51. Joint United Nations Programme on HIV/AIDS. World AIDS Day Report - 2011. Geneva: UNAIDS; 2011. Available from: http://www.unaids. org/en/media/unaids/contentassets/documents/unaidspublication/2011/ jc2216_worldaidsday_report_2011_en.pdf. Accessed February 13, 2014.

52. Gordon SB, Walsh AL, Chaponda M, et al. Bacterial meningitis in Malawian adults: pneumococcal disease is common, severe, and seasonal. Clin Infect Dis. 2000;31:53-57.

53. Heyderman RS, Gangaidzo IT, Hakim JG, et al. Cryptococcal meningitis in human immunodeficiency virus-infected patients in Harare, Zimbabwe. Clin Infect Dis. 1998;26:284-289.

54. Hakim JG, Gangaidzo IT, Heyderman RS, et al. Impact of HIV infection on meningitis in Harare, Zimbabwe: a prospective study of 406 predominantly adult patients. AIDS. 2000;14:1401-1407.

55. Schutte CM, Van der Meyden CH, Magazi DS. The impact of HIV on meningitis as seen at a South African academic hospital (1994 to 1998). Infection. 2000;28:3-7.

56. Bisson GP, Lukes J, Thakur R, Mtoni I, MacGregor RR. Cryptococcus and lymphocytic meningitis in Botswana. S Afr Med J. 2008;98: 724-725.

57. Harling G, Orrell C, Wood R. Healthcare utilization of patients accessing an African national treatment program. BMC Health Serv Res. 2007;7:80.

58. Nissapatorn V. Lessons learned about opportunistic infections in Southeast Asia. Southeast Asian J Trop Med Public Health. 2008;39:625-641.

59. Leimann BC, Koifman RJ. Cryptococcal meningitis in Rio de Janeiro State, Brazil, 1994-2004. Cad Saude Publica. 2008;24:2582-2592.

60. Lortholary O, Poizat G, Zeller V, et al. Long-term outcome of AIDSassociated cryptococcosis in the era of combination antiretroviral therapy. AIDS. 2006;20:2183-2191.

61. Antinori S, Ridolfo A, Fasan M, et al. AIDS-associated cryptococcosis: a comparison of epidemiology, clinical features and outcome in the pre- and post-HAART eras. Experience of a single centre in Italy. $\mathrm{HIV}$ Med. 2009;10:6-11.

62. Kambugu A, Meya DB, Rhein J, et al. Outcomes of cryptococcal meningitis in Uganda before and after the availability of highly active antiretroviral therapy. Clin Infect Dis. 2008;46:1694-1701.

63. van der Horst CM, Saag MS, Cloud GA, et al. Treatment of cryptococcal meningitis associated with the acquired immunodeficiency syndrome. National Institute of Allergy and Infectious Diseases Mycoses Study Group and AIDS Clinical Trials Group. $N$ Engl J Med. 1997;337:15-21.

64. Bicanic T, Meintjes G, Wood R, et al. Fungal burden, early fungicidal activity, and outcome in cryptococcal meningitis in antiretroviral-naive or antiretroviral-experienced patients treated with amphotericin B or fluconazole. Clin Infect Dis. 2007;45:76-80.

65. Bicanic T, Wood R, Meintjes G, et al. High-dose amphotericin B with flucytosine for the treatment of cryptococcal meningitis in HIV-infected patients: a randomized trial. Clin Infect Dis. 2008;47:123-130.

66. Pitisuttithum P, Tansuphasawadikul S, Simpson AJ, Howe PA, White NJ. A prospective study of AIDS-associated cryptococcal meningitis in Thailand treated with high-dose amphotericin B. $J$ Infect. 2001;43:226-233.

67. Sloan DJ, Dedicoat MJ, Lalloo DG. Treatment of cryptococcal meningitis in resource limited settings. Curr Opin Infect Dis. 2009;22: 455-463.

68. Hay RJ, Mackenzie DW, Campbell CK, Philpot CM. Cryptococcosis in the United Kingdom and the Irish Republic: an analysis of 69 cases. J Infect. 1980;2:13-22.

69. Husain S, Wagener MM, Singh N. Cryptococcus neoformans infection in organ transplant recipients: variables influencing clinical characteristics and outcome. Emerg Infect Dis. 2001;7:375-381.

70. Slavin MA, Chen SC. Cryptococcosis, lymphoproliferative disorders and modern day chemotherapy regimens. Leuk Lymphoma. 2013;54:449-450.

71. Hage CA, Wood KL, Winer-Muram HT, Wilson SJ, Sarosi G, Knox KS. Pulmonary cryptococcosis after initiation of anti-tumor necrosis factor-alpha therapy. Chest. 2003;124:2395-2397.
72. Nath DS, Kandaswamy R, Gruessner R, Sutherland DE, Dunn DL, Humar A. Fungal infections in transplant recipients receiving alemtuzumab. Transplant Proc. 2005;37:934-936.

73. Bratton EW, El Husseini N, Chastain CA, et al. Comparison and temporal trends of three groups with cryptococcosis: HIV-infected, solid organ transplant, and HIV-negative/non-transplant. PLoS One. 2012;7:e43582.

74. Neofytos D, Fishman JA, Horn D, et al. Epidemiology and outcome of invasive fungal infections in solid organ transplant recipients. Transpl Infect Dis. 2010;12:220-229.

75. Sun HY, Alexander BD, Lortholary O, et al. Unrecognized pretransplant and donor-derived cryptococcal disease in organ transplant recipients. Clin Infect Dis. 2010;51:1062-1069.

76. Baddley JW, Schain DC, Gupte AA, et al. Transmission of Cryptococcus neoformans by organ transplantation. Clin Infect Dis. 2011;52: e94-e98.

77. Singh N, Huprikar S, Burdette SD, Morris MI, Blair JE, Wheat LJ. Donor-derived fungal infections in organ transplant recipients: guidelines of the American Society of Transplantation, infectious diseases community of practice. Am J Transplant. 2012;12:2414-2428.

78. Sun HY, Wagener MM, Singh N. Cryptococcosis in solid-organ, hematopoietic stem cell, and tissue transplant recipients: evidence-based evolving trends. Clin Infect Dis. 2009;48:1566-1576.

79. Pappas PG, Alexander BD, Andes DR, et al. Invasive fungal infections among organ transplant recipients: results of the Transplant-Associated Infection Surveillance Network (TRANSNET). Clin Infect Dis. 2010;50:1101-1111

80. Kontoyiannis DP, Marr KA, Park BJ, et al. Prospective surveillance for invasive fungal infections in hematopoietic stem cell transplant recipients, 2001-2006: overview of the Transplant-Associated Infection Surveillance Network (TRANSNET) database. Clin Infect Dis. 2010;50: 1091-1100.

81. Nguyen MH, Husain S, Clancy CJ, et al. Outcomes of central nervous system cryptococcosis vary with host immune function: results from a multi-center, prospective study. J Infect. 2010;61:419-426.

82. Dromer F, Mathoulin S, Dupont B, Laporte A. Epidemiology of cryptococcosis in France: a 9-year survey (1985-1993). French Cryptococcosis Study Group. Clin Infect Dis. 1996;23:82-90.

83. Singh N, Alexander BD, Lortholary O, et al. Cryptococcus neoformans in organ transplant recipients: impact of calcineurin-inhibitor agents on mortality. J Infect Dis. 2007;195:756-764.

84. Shaariah W, Morad Z, Suleiman AB. Cryptococcosis in renal transplant recipients. Transplant Proc. 1992;24:1898-1899.

85. Chen S, Sorrell T, Nimmo G, et al. Epidemiology and host- and varietydependent characteristics of infection due to Cryptococcus neoformans in Australia and New Zealand. Australasian Cryptococcal Study Group. Clin Infect Dis. 2000;31:499-508.

86. Mwaba P, Mwansa J, Chintu C, et al. Clinical presentation, natural history, and cumulative death rates of 230 adults with primary cryptococcal meningitis in Zambian AIDS patients treated under local conditions. Postgrad Med J. 2001;77:769-773.

87. Rothe C, Sloan DJ, Goodson P, et al. A prospective longitudinal study of the clinical outcomes from cryptococcal meningitis following treatment induction with $800 \mathrm{mg}$ oral fluconazole in Blantyre, Malawi. PLoS One. 2013;8:e67311.

88. Seaton RA, Verma N, Naraqi S, Wembri JP, Warrell DA. The effect of corticosteroids on visual loss in Cryptococcus neoformans var. gattii meningitis. Trans R Soc Trop Med Hyg. 1997;91:50-52.

89. Seaton RA, Verma N, Naraqi S, Wembri JP, Warrell DA. Visual loss in immunocompetent patients with Cryptococcus neoformans var. gattii meningitis. Trans R Soc Trop Med Hyg. 1997;91:44-49.

90. Lesser RL, Simon RM, Leon H, Siegel N. Cryptococcal meningitis and internal ophthalmoplegia. Am J Ophthalmol. 1979;87:682-687.

91. Kestelyn P, Taelman H, Bogaerts J, et al. Ophthalmic manifestations of infections with Cryptococcus neoformans in patients with the acquired immunodeficiency syndrome. Am J Ophthalmol. 1993;116: $721-727$. 
92. Lalloo D, Fisher D, Naraqi S, et al. Cryptococcal meningitis (C. neoformans var. gattii) leading to blindness in previously healthy Melanesian adults in Papua New Guinea. Q J Med. 1994;87:343-349.

93. Trachtenberg JD, Kambugu AD, McKellar M, et al. The medical management of central nervous system infections in Uganda and the potential impact of an algorithm-based approach to improve outcomes. Int J Infect Dis. 2007;11:524-530.

94. Moosa MY, Coovadia YM. Cryptococcal meningitis in Durban, South Africa: a comparison of clinical features, laboratory findings, and outcome for human immunodeficiency virus (HIV)-positive and HIV-negative patients. Clin Infect Dis. 1997;24:131-134.

95. Kabanda T, Siedner MJ, Klausner JD, Muzoora C, Boulware DR. Pointof-care diagnosis and prognostication of cryptococcal meningitis with the cryptococcal antigen lateral flow assay on cerebrospinal fluid. Clin Infect Dis. 2014;58:113-116.

96. Rugemalila J, Maro VP, Kapanda G, Ndaro AJ, Jarvis JN. Cryptococcal antigen prevalence in HIV-infected Tanzanians: a cross-sectional study and evaluation of a point-of-care lateral flow assay. Trop Med Int Health. 2013;18:1075-1079.

97. McMullan BJ, Halliday C, Sorrell TC, et al. Clinical utility of the cryptococcal antigen lateral flow assay in a diagnostic mycology laboratory. PLoS One. 2012;7:e49541.

98. Jarvis JN, Percival A, Bauman S, et al. Evaluation of a novel pointof-care cryptococcal antigen test on serum, plasma, and urine from patients with HIV-associated cryptococcal meningitis. Clin Infect Dis. 2011;53:1019-1023.

99. World Health Organization. Rapid Advice: Diagnosis, Prevention and Management of Cryptococcal Disease in HIV-Infected Adults, Adolescents and Children. Geneva: WHO; 2011. Available from: http://whqlibdoc.who.int/publications/2011/9789241502979_eng.pdf. Accessed February 13, 2014.

100. Brouwer AE, Rajanuwong A, Chierakul W, et al. Combination antifungal therapies for HIV-associated cryptococcal meningitis: a randomised trial. Lancet. 2004;363:1764-1767.

101. Bicanic T, Muzoora C, Brouwer AE, et al. Independent association between rate of clearance of infection and clinical outcome of HIVassociated cryptococcal meningitis: analysis of a combined cohort of 262 patients. Clin Infect Dis. 2009;49:702-709.

102. Andes D. Pharmacokinetics and pharmacodynamics of antifungals. Infect Dis Clin North Am. 2006;20:679-697.

103. Denning DW, Hope WW. Therapy for fungal diseases: opportunities and priorities. Trends Microbiol. 2010;18:195-204.

104. Cornely OA, Maertens J, Bresnik M, et al. Liposomal amphotericin B as initial therapy for invasive mold infection: a randomized trial comparing a high-loading dose regimen with standard dosing (AmBiLoad trial). Clin Infect Dis. 2007;44:1289-1297.

105. Hamill RJ, Sobel JD, El-Sadr W, et al. Comparison of 2 doses of liposomal amphotericin B and conventional amphotericin B deoxycholate for treatment of AIDS-associated acute cryptococcal meningitis: a randomized, double-blind clinical trial of efficacy and safety. Clin Infect Dis. 2010;51:225-232.

106. Leenders AC, Reiss P, Portegies P, et al. Liposomal amphotericin B (AmBisome) compared with amphotericin B both followed by oral fluconazole in the treatment of AIDS-associated cryptococcal meningitis. AIDS. 1997;11:1463-1471.

107. Chen SC. Cryptococcosis in Australasia and the treatment of cryptococcal and other fungal infections with liposomal amphotericin B. J Antimicrob Chemother. 2002;49 Suppl 1:57-61.

108. Bicanic T, Ogden D, Whitney L, Loyse A, Jarvis J. British HIV Association opportunistic infection guidelines: in defence of amphotericin B deoxycholate. HIV Med. 2012;13:636-637.

109. Pappas PG, Chetchotisakd P, Larsen RA, et al. A phase II randomized trial of amphotericin B alone or combined with fluconazole in the treatment of HIV-associated cryptococcal meningitis. Clin Infect Dis. 2009;48:1775-1783.

110. Rajasingham R, Meya DB, Boulware DR. Integrating cryptococcal antigen screening and pre-emptive treatment into routine HIV care. J Acquir Immune Defic Syndr. 2012;59:e85-e91.
111. Jackson AT, Nussbaum JC, Phulusa J, et al. A phase II randomized controlled trial adding oral flucytosine to high-dose fluconazole, with short-course amphotericin B, for cryptococcal meningitis. AIDS. 2012;26:1363-1370.

112. Butler EK, Boulware DR, Bohjanen PR, Meya DB. Long term 5-year survival of persons with cryptococcal meningitis or asymptomatic subclinical antigenemia in Uganda. PLoS One. 2012;7:e51291.

113. Day JN, Chau TT, Lalloo DG. Combination antifungal therapy for cryptococcal meningitis. N Engl J Med. 2013;368:2522-2523.

114. Loyse A, Dromer F, Day J, Lortholary O, Harrison TS. Flucytosine and cryptococcosis: time to urgently address the worldwide accessibility of a 50-year-old antifungal. J Antimicrob Chemother. 2013;68: 2435-2444.

115. O'Connor L, Livermore J, Sharp AD, et al. Pharmacodynamics of liposomal amphotericin B and flucytosine for cryptococcal meningoencephalitis: safe and effective regimens for immunocompromised patients. J Infect Dis. 2013;208:351-361.

116. Dromer F, Bernede-Bauduin C, Guillemot D, Lortholary O. Major role for amphotericin B-flucytosine combination in severe cryptococcosis. PLoS One. 2008;3:e2870.

117. Saag MS, Cloud GA, Graybill JR, et al. A comparison of itraconazole versus fluconazole as maintenance therapy for AIDS-associated cryptococcal meningitis. National Institute of Allergy and Infectious Diseases Mycoses Study Group. Clin Infect Dis. 1999;28:291-296.

118. Andes D, Pascual A, Marchetti O. Antifungal therapeutic drug monitoring: established and emerging indications. Antimicrob Agents Chemother. 2009;53:24-34.

119. Bicanic T, Wood R, Bekker LG, Darder M, Meintjes G, Harrison TS. Antiretroviral roll-out, antifungal roll-back: access to treatment for cryptococcal meningitis. Lancet Infect Dis. 2005;5:530-531.

120. Loyse A, Thangaraj H, Easterbrook P, et al. Cryptococcal meningitis: improving access to essential antifungal medicines in resource-poor countries. Lancet Infect Dis. 2013;13:629-637.

121. Muzoora CK, Kabanda T, Ortu G, et al. Short course amphotericin B with high dose fluconazole for HIV-associated cryptococcal meningitis. J Infect. 2012;64:76-81.

122. Loyse A, Wilson D, Meintjes G, et al. Comparison of the early fungicidal activity of high-dose fluconazole, voriconazole, and flucytosine as second-line drugs given in combination with amphotericin B for the treatment of HIV-associated cryptococcal meningitis. Clin Infect Dis. 2012;54:121-128.

123. Rajasingham R, Rolfes MA, Birkenkamp KE, Meya DB, Boulware DR. Cryptococcal meningitis treatment strategies in resource-limited settings: a cost-effectiveness analysis. PLoS Med. 2012;9:e1001316.

124. Mayanja-Kizza H, Oishi K, Mitarai S, et al. Combination therapy with fluconazole and flucytosine for cryptococcal meningitis in Ugandan patients with AIDS. Clin Infect Dis. 1998;26:1362-1366.

125. Schaars CF, Meintjes GA, Morroni C, Post FA, Maartens G. Outcome of AIDS-associated cryptococcal meningitis initially treated with $200 \mathrm{mg} /$ day or $400 \mathrm{mg} /$ day of fluconazole. BMC Infect Dis. 2006;6:118.

126. Longley N, Muzoora C, Taseera K, et al. Dose response effect of high-dose fluconazole for HIV-associated cryptococcal meningitis in southwestern Uganda. Clin Infect Dis. 2008;47:1556-1561.

127. Nussbaum JC, Jackson A, Namarika D, et al. Combination flucytosine and high-dose fluconazole compared with fluconazole monotherapy for the treatment of cryptococcal meningitis: a randomized trial in Malawi. Clin Infect Dis. 2010;50:338-344.

128. Sudan A, Livermore J, Howard SJ, et al. Pharmacokinetics and pharmacodynamics of fluconazole for cryptococcal meningoencephalitis: implications for antifungal therapy and in vitro susceptibility breakpoints. Antimicrob Agents Chemother. 2013;57:2793-2800.

129. Milefchik E, Leal MA, Haubrich R, et al. Fluconazole alone or combined with flucytosine for the treatment of AIDS-associated cryptococcal meningitis. Med Mycol. 2008;46:393-395.

130. St George's University of London (UK). Advancing Cryptococcal meningitis Treatment for Africa: Oral fluconazole plus flucytosine or one week amphotericin B-based therapy vs two weeks amphotericin B-based therapy for initial treatment of HIV-associated cryptococcal meningitis. Available from: http://www.controlled-trials.com/ISRCTN45035509. ISRCTN identifier: ISRCTN45035509. Accessed February 28, 2014. 
131. Bozzette SA, Larsen RA, Chiu J, et al. A placebo-controlled trial of maintenance therapy with fluconazole after treatment of cryptococcal meningitis in the acquired immunodeficiency syndrome. California Collaborative Treatment Group. N Engl J Med. 1991;324: 580-584.

132. Powderly WG, Saag MS, Cloud GA, et al. A controlled trial of fluconazole or amphotericin B to prevent relapse of cryptococcal meningitis in patients with the acquired immunodeficiency syndrome. The NIAID AIDS Clinical Trials Group and Mycoses Study Group. N Engl J Med 1992;326:793-798.

133. Collett G, Parrish A. Fluconazole donation and outcomes assessment in cryptococcal meningitis. S Afr Med J. 2007;97:175-176.

134. Jarvis JN, Meintjes G, Williams Z, Rebe K, Harrison TS. Symptomatic relapse of HIV-associated cryptococcal meningitis in South Africa: the role of inadequate secondary prophylaxis. S Afr Med J. 2010;100: 378-382.

135. Mussini C, Pezzotti P, Miro JM, et al. Discontinuation of maintenance therapy for cryptococcal meningitis in patients with AIDS treated with highly active antiretroviral therapy: an international observational study. Clin Infect Dis. 2004;38:565-571.

136. Vibhagool A, Sungkanuparph S, Mootsikapun P, et al. Discontinuation of secondary prophylaxis for cryptococcal meningitis in human immunodeficiency virus-infected patients treated with highly active antiretroviral therapy: a prospective, multicenter, randomized study. Clin Infect Dis. 2003;36:1329-1331.

137. Martínez E, García-Viejo MA, Marcos MA, et al. Discontinuation of secondary prophylaxis for cryptococcal meningitis in HIV-infected patients responding to highly active antiretroviral therapy. AIDS. 2000;14:2615-2617.

138. Rollot F, Bossi P, Tubiana R, et al. Discontinuation of secondary prophylaxis against cryptococcosis in patients with AIDS receiving highly active antiretroviral therapy. AIDS. 2001;15:1448-1449.

139. Seddon J, Mangeya N, Miller RF, Corbett EL, Ferrand RA. Recurrence of cryptococcal meningitis in HIV-infected patients following immune reconstitution. Int J STD AIDS. 2009;20:274-275.

140. Singh N, Lortholary O, Alexander BD, et al. An immune reconstitution syndrome-like illness associated with Cryptococcus neoformans infection in organ transplant recipients. Clin Infect Dis. 2005;40: 1756-1761.

141. Singh N, Perfect JR. Immune reconstitution syndrome associated with opportunistic mycoses. Lancet Infect Dis. 2007;7:395-401.

142. Singh N, Lortholary O, Alexander BD, et al. Antifungal management practices and evolution of infection in organ transplant recipients with Cryptococcus neoformans infection. Transplantation. 2005;80:1033-1039.

143. Morera-López Y, Torres-Rodríguez JM, Jiménez-Cabello T, Baró-Tomás T. Cryptococcus gattii: in vitro susceptibility to the new antifungal albaconazole versus fluconazole and voriconazole. Med Mycol. 2005;43:505-510.

144. Chong HS, Dagg R, Malik R, Chen S, Carter D. In vitro susceptibility of the yeast pathogen cryptococcus to fluconazole and other azoles varies with molecular genotype. J Clin Microbiol. 2010;48:4115-4120.

145. Smith RM, Nguyen TA, Ha HT, et al. Prevalence of cryptococcal antigenemia and cost-effectiveness of a cryptococcal antigen screening program - Vietnam. PLoS One. 2013;8:e62213.

146. Beyene T, Woldeamanuel Y, Asrat D, Ayana G, Boulware DR Comparison of cryptococcal antigenemia between antiretroviral naive and antiretroviral experienced HIV positive patients at two hospitals in Ethiopia. PLoS One. 2013;8:e75585.

147. Alemu AS, Kempker RR, Tenna A, et al. High prevalence of cryptococcal antigenemia among HIV-infected patients receiving antiretroviral therapy in Ethiopia. PLoS One. 2013;8:e58377.

148. French N, Gray K, Watera C, et al. Cryptococcal infection in a cohort of HIV-1-infected Ugandan adults. AIDS. 2002;16:1031-1038.

149. Liechty CA, Solberg P, Were W, et al. Asymptomatic serum cryptococcal antigenemia and early mortality during antiretroviral therapy in rural Uganda. Trop Med Int Health. 2007;12:929-935.

150. Govender NP, Chetty V, Roy M, et al. Phased implementation of screening for cryptococcal disease in South Africa. S Afr Med J. 2012;102:914-917.
151. Jarvis JN, Harrison TS, Lawn SD, Meintjes G, Wood R, Cleary S. Cost effectiveness of cryptococcal antigen screening as a strategy to prevent HIV-associated cryptococcal meningitis in South Africa. PLoS One. 2013;8:e69288

152. Jarvis JN, Lawn SD, Vogt M, Bangani N, Wood R, Harrison TS. Screening for cryptococcal antigenemia in patients accessing an antiretroviral treatment program in South Africa. Clin Infect Dis. 2009;48:856-862.

153. Meya DB, Manabe YC, Castelnuovo B, et al. Cost-effectiveness of serum cryptococcal antigen screening to prevent deaths among HIV-infected persons with a CD4+ cell count $\leq 100$ cells/microL who start HIV therapy in resource-limited settings. Clin Infect Dis. 2010;51:448-455.

154. Jarvis JN, Govender N, Chiller T, et al. Cryptococcal antigen screening and preemptive therapy in patients initiating antiretroviral therapy in resource-limited settings: a proposed algorithm for clinical implementation. J Int Assoc Physicians AIDS Care (Chic). 2012;11:374-379.

155. Meyer AC, Kendi CK, Penner JA, et al. The impact of routine cryptococcal antigen screening on survival among HIV-infected individuals with advanced immunosuppression in Kenya. Trop Med Int Health. 2013;18:495-503.

156. Chang LW, Phipps WT, Kennedy GE, Rutherford GW. Antifungal interventions for the primary prevention of cryptococcal disease in adults with HIV. Cochrane Database Syst Rev. 2005:CD004773.

157. Parkes-Ratanshi R, Wakeham K, Levin J, et al. Primary prophylaxis of cryptococcal disease with fluconazole in HIV-positive Ugandan adults: a double-blind, randomised, placebo-controlled trial. Lancet Infect Dis. 2011;11:933-941.

158. Apisarnthanarak A, Mundy LM. The impact of primary prophylaxis for cryptococcosis on fluconazole resistance in Candida species. J Acquir Immune Defic Syndr. 2008;47:644-645.

159. Bicanic T, Brouwer AE, Meintjes G, et al. Relationship of cerebrospinal fluid pressure, fungal burden and outcome in patients with cryptococcal meningitis undergoing serial lumbar punctures. AIDS. 2009;23:701-706.

160. Graybill JR, Sobel J, Saag M, et al. Diagnosis and management of increased intracranial pressure in patients with AIDS and cryptococcal meningitis. The NIAID Mycoses Study Group and AIDS Cooperative Treatment Groups. Clin Infect Dis. 2000;30:47-54.

161. Pappas PG. Managing cryptococcal meningitis is about handling the pressure. Clin Infect Dis. 2005;40:480-482.

162. Dammert P, Bustamante B, Ticona E, et al. Treatment of cryptococcal meningitis in Peruvian AIDS patients using amphotericin B and fluconazole. J Infect. 2008;57:260-265.

163. de Vedia L, Arechavala A, Calderon MI, et al. Relevance of intracranial hypertension control in the management of Cryptococcus neoformans meningitis related to AIDS. Infection. 2013;41:1073-1077.

164. Wijewardana I, Jarvis JN, Meintjes G, Harrison TS, Bicanic T. Large volume lumbar punctures in cryptococcal meningitis clear cryptococcal antigen as well as lowering pressure. J Infect. 2011;63:484-486.

165. Manosuthi W, Sungkanuparph S, Chottanapund S, et al. Temporary external lumbar drainage for reducing elevated intracranial pressure in HIV-infected patients with cryptococcal meningitis. Int J STD AIDS. 2008;19:268-271.

166. Woodworth GF, McGirt MJ, Williams MA, Rigamonti D. The use of ventriculoperitoneal shunts for uncontrollable intracranial hypertension without ventriculomegally secondary to HIV-associated cryptococcal meningitis. Surg Neurol. 2005;63:529-531; discussion 531-532.

167. Newton PN, Thai le H, Tip NQ, et al. A randomized, double-blind, placebo-controlled trial of acetazolamide for the treatment of elevated intracranial pressure in cryptococcal meningitis. Clin Infect Dis. 2002;35:769-772.

168. Haddow LJ, Colebunders R, Meintjes G, et al. Cryptococcal immune reconstitution inflammatory syndrome in HIV-1-infected individuals: proposed clinical case definitions. Lancet Infect Dis 2010;10:791-802.

169. Lawn SD, Harries AD, Anglaret X, Myer L, Wood R. Early mortality among adults accessing antiretroviral treatment programmes in subSaharan Africa. AIDS. 2008;22:1897-1908. 
170. Bisson GP, Nthobatsong R, Thakur R, et al. The use of HAART is associated with decreased risk of death during initial treatment of cryptococcal meningitis in adults in Botswana. J Acquir Immune Defic Syndr. 2008;49:227-229.

171. Klotz SA, Aziz Mohammed A, Girmai Woldemichael M, Worku Mitku $\mathrm{M}$, Handrich M. Immune reconstitution inflammatory syndrome in a resource-poor setting. J Int Assoc Physicians AIDS Care (Chic). 2009;8:122-127.

172. Lawn SD, Bekker LG, Myer L, Orrell C, Wood R. Cryptococcocal immune reconstitution disease: a major cause of early mortality in a South African antiretroviral programme. AIDS. 2005;19:2050-2052.

173. Murdoch DM, Venter WD, Feldman C, Van Rie A. Incidence and risk factors for the immune reconstitution inflammatory syndrome in HIV patients in South Africa: a prospective study. AIDS. 2008;22:601-610.

174. French MA. HIV/AIDS: immune reconstitution inflammatory syndrome: a reappraisal. Clin Infect Dis. 2009;48:101-107.

175. Longley N, Harrison TS, Jarvis JN. Cryptococcal immune reconstitution inflammatory syndrome. Curr Opin Infect Dis. 2013;26:26-34.

176. Lortholary O, Fontanet A, Memain N, Martin A, Sitbon K, Dromer F. Incidence and risk factors of immune reconstitution inflammatory syndrome complicating HIV-associated cryptococcosis in France. AIDS. 2005;19:1043-1049.

177. Bicanic T, Meintjes G, Rebe K, et al. Immune reconstitution inflammatory syndrome in HIV-associated cryptococcal meningitis: a prospective study. J Acquir Immune Defic Syndr. 2009;51:130-134.

178. Lesho E. Evidence base for using corticosteroids to treat HIVassociated immune reconstitution syndrome. Expert Rev Anti Infect Ther. 2006;4:469-478.
179. Chang C, Dorasamay A, Elliott J, et al. HIV+ patients with CM who attain CSF sterility pre-cART commencement experience improved outcomes in the first 24 weeks. Poster presented at: 19th Conference on Retroviruses and Opportunistic Infections; March 5-8, 2012; Seattle, WA.

180. Jackson A, van der Horst C. New insights in the prevention, diagnosis, and treatment of cryptococcal meningitis. Curr HIV/AIDS Rep. 2012;9:267-277.

181. Manosuthi W, Chottanapund S, Sungkanuparph S. Mortality rate of early versus deferred initiation of antiretroviral therapy in HIV-1infected patients with cryptococcal meningitis. JAcquir Immune Defic Syndr. 2008;48:508-509.

182. Zolopa A, Andersen J, Powderly W, et al. Early antiretroviral therapy reduces AIDS progression/death in individuals with acute opportunistic infections: a multicenter randomized strategy trial. PLoS One. 2009;4:e5575.

183. Bisson GP, Molefi M, Bellamy S, et al. Early versus delayed antiretroviral therapy and cerebrospinal fluid fungal clearance in adults with HIV and cryptococcal meningitis. Clin Infect Dis. 2013;56:1165-1173.

184. Makadzange AT, Ndhlovu CE, Takarinda K, et al. Early versus delayed initiation of antiretroviral therapy for concurrent HIV infection and cryptococcal meningitis in sub-Saharan Africa. Clin Infect Dis. 2010;50:1532-1538.

185. Boulware D, Meya D, Muzoora C, et al. ART initiation within the first 2 weeks of cryptococcal meningitis is associated with higher mortality: a multisite randomized trial. Poster presented at: 20th Conference on Retroviruses and Opportunistic Infections; March 3-6, 2013; Atlanta, GA.
Clinical Epidemiology

\section{Publish your work in this journal}

Clinical Epidemiology is an international, peer-reviewed, open access journal focusing on disease and drug epidemiology, identification of risk factors and screening procedures to develop optimal preventative initiatives and programs. Specific topics include: diagnosis, prognosis, treatment, screening, prevention, risk factor modification, systematic

Submit your manuscript here: http://www.dovepress.com/clinical-epidemiology-journal

\section{Dovepress}

reviews, risk \& safety of medical interventions, epidemiology \& biostatical methods, evaluation of guidelines, translational medicine, health policies \& economic evaluations. The manuscript management system is completely online and includes a very quick and fair peer-review system, which is all easy to use. 